\title{
Color stability and surface roughness of chitosan- and nanodiamond-modified bisacrylic resin
}

\section{Victoria Tamara PERCHYONOK(a) John SOUZA ${ }^{(b)}$ \\ Marcela Fernanda KÜLL(c) \\ Thaís Yumi Umeda SUZUKI(d) \\ Ana Teresa MALULY-PRONI(c) \\ Paulo Henrique dos SANTOS(c)}

(a)VTPCHEM PTY LTD, Research and

Innovations, Melbourne, Australia.

(b)TAFE Queensland Brisbane, Brisbane,

Australia.

(c) Universidade Estadual Paulista - UNESP, Araçatuba School of Dentistry, Department of Dental Materials and Prosthodontics, Araçatuba, São Paulo, Brazil.

(d) Universidade Federal de Minas Gerais UFMG, Faculty of Dentistry, Department of Restorative Dentistry, Belo Horizonte, Minas Gerais, Brazil.

Declaration of Interests: The authors certify that they have no commercial or associative interest that represents a conflict of interest in connection with the manuscript.

Corresponding Author:

Victoria Tamara Perchyonok

E-mail: tamaraperchyonok@gmail.com

https://doi.org/10.1590/1807-3107bor-2019.vol33.0024

Submitted: September 19, 2018

Accepted for publication: February 16, 2019

Last revision: February 27, 2019
Abstract: The aim of this study is to evaluate the effect of chitosan or nanodiamond incorporation on the color stability and surface roughness of a bisacrylic resin subjected to artificial aging. Four bisacrylic resins were evaluated, namely, control, chitosan-modified material, nanodiamond-modified material, and chitosan-nanodiamond-modified material. Twenty-four specimens were prepared for each material. The surface roughness was determined using a profilometer with a cut-off of $0.25 \mathrm{~mm}$. The baseline color was measured according to the CIE L*a*b* system using a reflectance spectrophotometer. After these tests, the specimens were individually immersed in cola soft drink, red wine, or distilled water $(n=8)$ for 28 days. After the aging, the surface roughness and final color were re-evaluated. The color stability was determined using the difference between the coordinates obtained before and after the aging process. The data on roughness and color change were evaluated using ANOVA and the Tukey test $(\alpha=0.05)$. The results show that the incorporation of nanodiamonds and chitosan into a bisacrylic resin provided a better color stability to the materials $(\mathrm{p}=0.007)$. The storage in red wine resulted in a higher variation in the surface roughness values, especially when only the nanodiamond was incorporated to the material $(\mathrm{p}<0.05)$. The incorporation of both chitosan and nanodiamonds are promising in providing an improvement in the properties of the bisacrylic resin when they are simultaneously incorporated in the product.

Keywords: Color; Surface Properties; Dental Restoration, Temporary; Chitosan; Nanodiamonds.

\section{Introduction}

Temporary restorations are clinical procedures to protect the remaining tooth structure during dental treatments, ${ }^{1}$ which are especially crucial in instances of prolonged treatment, laboratory protocols, and complex prosthodontics treatment. ${ }^{1,2}$ An adequate temporary restoration must preserve the structural/functional integrity of tissues during the treatment to achieve maximum therapeutic benefit and desired protection of the remaining structure. ${ }^{2,3}$

Temporary restorations are manufactured using a resin-based provisional crown and bridge materials ${ }^{4,5}$ and can be divided into four 
groups according to their composition: polymethyl methacrylate (PMMA), polyethyl or butyl methacrylate, microfilled bisphenol A-glycidyl dimethacrylate composite resin, and urethane dimethacrylate (lightpolymerizing resins) ${ }^{6,7}$ Methyl methacrylates and bisacrylic resin are superior in terms of aesthetics and wear resistance compared with ethyl methacrylates. ${ }^{8,9}$ Bisacrylic resin is a relatively new temporary material and has been clinically accepted owing to its simplicity in handling, desirable aesthetics, ease in polishing, and superior mechanical properties compared with conventional acrylic temporary resins..$^{10}$ Although temporary restorations may provide several benefits for rehabilitation treatment, they may also present disadvantages in long-term clinical functions, including material fractures..$^{10}$ Furthermore, the inclusion of reinforcement materials is one of the methods used to improve their properties. Metal wires and fibers have been studied as reinforcement for these materials. ${ }^{10,11}$

Nanodiamonds have become one of the most widely studied nanomaterials owing to their unique properties such as hardness, thermal conductivity, dopability, or optical transparency over a wide spectral range. ${ }^{12}$ Considering that the application of nanoparticles as fillers in polymeric matrices has been well documented in strengthening of materials, the incorporation of nanoparticles into dental polymeric materials can be expected to provide an enhancing effect on the mechanical properties of the resulting functional biomaterials. ${ }^{13,14,15}$ The incorporation of nanodiamonds in dental materials was shown to be effective in reinforcing the material, thus increasing its strength, surface properties, and biocompatibility. ${ }^{16}$

Several studies have described the adverse effects of acrylate-based resin at the cellular and tissue levels. ${ }^{17}$ The mechanisms of these adverse effects involve direct toxicity from the released or residual MMA monomer and oxidative stress. ${ }^{18}$ Chitosan, a polysaccharide derivative from chitin that can be found in the shell of crustaceans, ${ }^{19,20}$ has been shown to be biocompatible, has no cytotoxicity and antibacterial effects, and optimizes drug release..$^{21,22,23}$ It is degraded by enzymes into oligosaccharides that are promptly resorbed and which can form a porous interconnected three-dimensional (3D) structure; thus, it can be applied to tissue-engineering purposes as a scaffolding biomaterial..$^{19}$ On the basis of these advantages, chitosan has been combined with other biomaterials in an attempt to improve the biological and mechanical properties. ${ }^{14}$ The application of chitosan materials in dentistry, including modification of dentifrices or incorporation in some materials, as glass ionomer cements, has shown promising results. ${ }^{24}$

Any modification in the composition of dental materials must importantly improve or at least do not alter the aesthetic properties and surface quality of the original material. If this modification results in a low color stability, the durability of the temporary restoration can be compromised, whereas modification in the surface roughness can result in plaque accumulation at levels that are not clinically acceptable. ${ }^{25}$ On this basis, the objective of this study is to examine the effect of additives such as chitosan and nanodiamond on the color stability and surface roughness of bisacrylic resin for temporary restorations subjected to artificial aging. Two null hypotheses were tested: the incorporation of chitosan or nanodiamond do not cause a difference in the color stability and surface roughness of a bisacrylic resin and different aging solutions do not modify the color stability and surface roughness of all studied materials.

\section{Methodology}

\section{Sample preparation}

Four bisacrylic resins were used: control (Protemp 4, 3M ESPE, St Paul, USA), 5\% chitosanmodified material, 5\% nanodiamond-modified material, and $2.5 \%$ chitosan- $2.5 \%$ nanodiamondmodified material. The chitosan, which has a degree of deacetylation of $90 \%$ and $375 \mathrm{kDa}$ molecular weight (Sigma-Aldrich, Saint Louis, USA), and the nanodiamonds with carbon nanoparticles with a diameter of approximately 2 to $8 \mathrm{~nm}$ (Ebersoles, Nürnberg, Germany) were used in this study as purchased. The chitosan and/or nanodiamond was directly incorporated in the bisacrylic resin in a larger section of the syringe of Protemp 4 and mixed using mechanical (5 $\mathrm{min}$ ) and ultrasonic (3 min) mixing to achieve homogeneous consistency 
(Table 1). The incorporation of chitosan and nanodiamond was confirmed by FT-IR (FTIR 8400, Shimadzu Corp., Kyoto, Japan) using the $\mathrm{KBr}$ method. Twenty-four specimens measuring $6 \mathrm{~mm} \times 1.5 \mathrm{~mm}$ were prepared for each material for a total of 96 specimens. A metallic mould was filled with these materials and covered with a polyester strip and a glass slide, which was compressed to remove the excess materials and prevent bubble formation. ${ }^{26}$ The materials were set for $5 \mathrm{~min}$. To guarantee complete polymerization, the specimens were stored for $24 \mathrm{~h}$ at $37^{\circ} \mathrm{C}$ and $100 \%$ relative humidity. ${ }^{26}$ After this period, the specimens were polished by $360-, 600-$, and 1200 -grit abrasive papers using a polishing machine (APL-4; Arotec Ind. Com., Cotia, Brazil) under water refrigeration and finished with diamond abrasive solution $(6,3$, and $1 \mu \mathrm{m}$ ) for $4 \mathrm{~min}$ each. In between the polishing and finishing procedure steps and after the entire process, the specimens were washed with deionized water for 2 min using an ultrasonic cleaner (model 2210; Branson Ultrasonics Corp., Danbury, USA). ${ }^{26}$

\section{Surface roughness test}

A profilometer was used to measure the surface roughness (Surftest SJ-400; Mitutoyo Corp., Kanagawa, Japan). The needle of the profilometer was positioned at the surface of the specimens and by employing a $0.25-\mathrm{mm}$ cut-off at $0.01 \mathrm{~mm} / \mathrm{s}$, three measurements of the $R a$ (arithmetical mean of the surface roughness) and $R z$ values (vertical distance from the highest peak to the lowest valley) were performed. ${ }^{25}$ Each measurement was obtained after turning the specimen by approximately $120^{\circ}$.

\section{Color measurement}

The same samples were then submitted to color analysis. Three color measurements were performed per sample by a reflectance spectrophotometer (UV-2450; Shimadzu Corp., Kyoto, Japan) using the CIE L*a* $\mathrm{b}^{*}$ color scale (Commission Internationale de I'Eclairage) with standard illuminant D65 observer functions (two-degree visual field) in the wavelength range of $360-740 \mathrm{~nm}$. The color scale was composed of a 3D color measurement: L* (luminosity coordinate), which ranges from 0 (perfect black) to 100 (perfect white), a* (green-red chromaticity), and b* (blue-yellow chromaticity). ${ }^{26}$

\section{Aging procedure}

After the measurement, the specimens of each bisacrylic resin were individually immersed in containers with cola soft drinks (Pepsi, PepsiCo, Rio de Janeiro, Brazil) with $\mathrm{pH}$ of 2.53, red wine with $\mathrm{pH}$ of 3.66 (120 Cabernet Sauvignon; Santa Rita, Santiago, Chile), or distilled water with $\mathrm{pH}$ of 6.37 for a storage period of four weeks ${ }^{26}$ at $37^{\circ} \mathrm{C}(\mathrm{n}=8)(\mathrm{ECB}-2$, Adamo Products Ltda., Piracicaba, Brazil). The solutions were renewed once a week.

After the storage, new measurements of the surface roughness $(R a$ and $R z)$ and color were performed following the same procedure described earlier.

Table 1. Materials used.

\begin{tabular}{|c|c|c|}
\hline Material & Description & Manufacturer \\
\hline Control & $\begin{array}{l}\text { Bisacrylic resin: ethanol,2,2' -[(1-methylidylidene)bis }(4,1 \text { - } \\
\text { phenylenoxy)]bis-, diacetate; silane-treated silica; benzyl-phenyl- } \\
\text { barbituric acid; terc-butyl 3,5,5-trimethyl peroxyhexanoate }\end{array}$ & Protemp 4 / 3M ESPE \\
\hline Chitosan-modified material & $\begin{array}{l}5 \% \text { weight chitosan added to bisacrylic resin and thoroughly mixed } \\
\text { using mechanical ( } 5 \mathrm{~min} \text { ) and ultrasonic mixing ( } 3 \mathrm{~min}) \text { in order to } \\
\text { achieve homogeneous consistency. }\end{array}$ & $\begin{array}{l}\text { Chitosan / Sigma-Aldrich } \\
\text { Protemp } 4 \text { / 3M ESPE }\end{array}$ \\
\hline Nanodiamond-modified material & $\begin{array}{l}5 \% \text { weight } 2-8 \mu \mathrm{m} \text { nanodiamond added to bisacrylic resin and } \\
\text { thoroughly mixed using mechanical ( } 5 \mathrm{~min} \text { ) and ultrasonic mixing ( } 3 \\
\mathrm{~min} \text { ) in order to achieve homogeneous consistency. }\end{array}$ & $\begin{array}{l}\text { Nanodiamond / Ebersoles } \\
\text { Protemp } 4 \text { / 3M ESPE }\end{array}$ \\
\hline $\begin{array}{l}\text { Chitosan- nanodiamond- modified } \\
\text { material }\end{array}$ & $\begin{array}{c}2,5 \% \text { weight chitosan }+2,5 \% \text { weight } 2-8 \mu \mathrm{m} \text { nanodiamond added } \\
\text { to bisacrylic resin and thoroughly mixed using mechanical (5 min) } \\
\text { and ultrasonic mixing ( } 3 \mathrm{~min} \text { ) in order to achieve homogeneous } \\
\text { consistency. }\end{array}$ & $\begin{array}{c}\text { Chitosan / Sigma-Aldrich } \\
\text { Nanodiamond / Ebersoles } \\
\text { Protemp } 4 \text { / 3M ESPE }\end{array}$ \\
\hline
\end{tabular}




\section{Color stability analysis}

After the new measurements of color in the 3D color measurement $\left(\mathrm{L}^{*}, \mathrm{a}^{*}\right.$ and $\left.\mathrm{b}^{*}\right), \Delta E$ between the color coordinates before (baseline) and after the aging treatment was calculated using the formula $\Delta E=\left[\left(\Delta L^{*}\right)^{2}\right.$ $\left.+\left(\Delta a^{*}\right)^{2}+\left(\Delta b^{*}\right)^{2}\right]^{1 / 22}$.22 The mean values were compared in terms of the tested materials and aging methods.

\section{SEM image}

For the scanning electron microscopy (SEM) image, one specimen from each group (control, chitosanmodified material, nanodiamond-modified material, and chitosan-nanodiamond-modified material) was prepared following the above-described process. The specimens were coated with Au-Pd alloy in vacuum and observed at $300 \times$ magnification using SEM (S4800, Hitachi, Japan) to characterize the surfaces.

\section{Statistical analysis}

The surface-roughness data $(R a$ and $R z)$ and color stability $(\Delta E)$ were subjected to a normality test (Shapiro-Wilk, Bioestat 5.3, Belém, Brazil). Two-way repeated analysis of variance (ANOVA) measurements were used for the surface roughness ( $R a$ and $R z$ ) for comparison of the means, followed by the Tukey test $(\alpha=0.05)$. The color stability mean values were subjected to two-way ANOVA and Tukey test $(\alpha=0.05)$ (Statview 5.0.1, SAS Institute Inc., Cary, USA).

\section{Results}

\section{Surface roughness}

Surface roughness values $R a$ and $R z$ are listed in Tables 2 and 3, respectively. No difference was observed among the evaluated materials before the aging and after storage in all solutions $(p>0.05)$. In the $\mathrm{Ra}$ and $\mathrm{Rz}$ analysis, in the nanodiamond-modified material, the storage in red wine resulted in an increase in the values of Ra surface roughness ( $p=0.015$ ). In the chitosan-nanodiamond-modified material, the storage in red wine showed higher values in the $\mathrm{Rz}$ surface roughness compared with the initial measurements $(p=0.023)$.

\section{Color stability $(\Delta E)$}

The results listed in Table 4 show that no difference was observed among the materials after storage in the cola soft drinks and red-wine solutions ( $p>0.05)$. however, after storage in the distilled water, the chitosan-nanodiamond-modified material exhibited higher color stability compared with the other materials. for the chitosan-modified

Table 2. Results of the Ra surface roughness of the materials before and after aging in different solutions.

\begin{tabular}{lcccc}
\hline Variable & Before aging & Distilled water & Cola & Red wine \\
\hline Control & $0.114 \pm 0.140 \mathrm{aA}$ & $0.089 \pm 0.100 \mathrm{aA}$ & $0.049 \pm 0.034 \mathrm{aA}$ & $0.039 \pm 0.006 \mathrm{aA}$ \\
Chitosan-modified material & $0.044 \pm 0.013 \mathrm{aA}$ & $0.067 \pm 0.028 \mathrm{aA}$ & $0.061 \pm 0.018 \mathrm{aA}$ & $0.072 \pm 0.037 \mathrm{aA}$ \\
Nanodiamond-modified material & $0.036 \pm 0.014 \mathrm{aA}$ & $0.054 \pm 0.019 \mathrm{abA}$ & $0.050 \pm 0.016 \mathrm{aA}$ & $0.074 \pm 0.030 \mathrm{bA}$ \\
Chitosan- nanodiamond- modified material & $0.030 \pm 0.008 \mathrm{aA}$ & $0.059 \pm 0.027 \mathrm{aA}$ & $0.056 \pm 0.027 \mathrm{aA}$ & $0.108 \pm 0.100 \mathrm{aA}$ \\
\hline
\end{tabular}

Different lower case letters indicate statistically significant differences $(p<0.05)$ among the solutions; Different upper case letters indicate statistically significant differences $(p<0.05)$ among the materials.

Table 3. Results of the Rz surface roughness of the materials before and after aging in different solutions.

\begin{tabular}{lcccc}
\hline Variable & Before aging & Distilled water & Cola & Red wine \\
\hline Control & $0.650 \pm 0.837 \mathrm{aA}$ & $0.525 \pm 0.587 \mathrm{aA}$ & $0.350 \pm 0.385 \mathrm{aA}$ & $0.288 \pm 0.064 \mathrm{aA}$ \\
Chitosan-modified material & $0.275 \pm 0.071 \mathrm{aA}$ & $0.475 \pm 0.243 \mathrm{aA}$ & $0.338 \pm 0.119 \mathrm{aA}$ & $0.425 \pm 0.175 \mathrm{aA}$ \\
Nanodiamond-modified material & $0.237 \pm 0.119 \mathrm{aA}$ & $0.325 \pm 0.104 \mathrm{aA}$ & $0.313 \pm 0.136 \mathrm{aA}$ & $0.450 \pm 0.120 \mathrm{bA}$ \\
Chitosan- nanodiamond-modified material & $0.200 \pm 0.053 \mathrm{aA}$ & $0.250 \pm 0.076 \mathrm{ab} \mathrm{A}$ & $0.287 \pm 0.173 \mathrm{abA}$ & $0.638 \pm 0.504 \mathrm{bA}$ \\
\hline
\end{tabular}

Different lower case letters indicate statistically significant differences $(p<0.05)$ among the solutions; Different upper case letters indicate statistically significant differences $(p<0.05)$ among the materials. 
Table 4. Results of color stability $(\Delta E)$ of the materials after aging in different solutions.

\begin{tabular}{lccc}
\hline Variable & Distilled water & Cola & Red wine \\
\hline Control & $12.92 \pm 7.53 \mathrm{aB}$ & $11.00 \pm 6.93 \mathrm{aA}$ & $11.15 \pm 6.81 \mathrm{aA}$ \\
Chitosan-modified material & $8.71 \pm 4.20 \mathrm{abB}$ & $14.73 \pm 7.86 \mathrm{bA}$ & $7.79 \pm 3.08 \mathrm{aA}$ \\
Nanodiamond-modified material & $8.81 \pm 5.88 \mathrm{aB}$ & $7.41 \pm 5.93 \mathrm{aA}$ & $12.24 \pm 7.87 \mathrm{aA}$ \\
Chitosan- nanodiamond-modified material & $5.24 \pm 2.13 \mathrm{aA}$ & $11.18 \pm 6.87 \mathrm{aA}$ & $8.29 \pm 4.84 \mathrm{aA}$ \\
\hline
\end{tabular}

Different lower case letters indicate statistically significant differences $(p<0.05)$ among aging solutions. Different upper case letters indicate statistically significant differences $(p<0.05)$ among the materials.

material, the storage in red wine exhibited higher color stability compared with that in the cola soft drinks $(p=0.038)$

\section{Discussion}

In the present study, the effects of the incorporation of chitosan and nanodiamond on the color stability and surface roughness of bisacrylic resin were evaluated. The use of substances such as chitosan and nanodiamond has been studied to improve the biocompatibility and mechanical properties of some materials, including temporary restorations. ${ }^{14}$ The results of the current study show that the incorporation of chitosan or nanodiamond did not cause a significant difference in the surfaceroughness values, and no significant differences in the SEM image was observed when compared with the control group (Figure). It is important to note that the surface roughness values, irrespective of the incorporation of chitosan or nanodiamond, remain below the critical surface-roughness threshold of 0.2 $\mu \mathrm{m}(R a)$ above which dental biofilm formation may occur, thus favoring the development of caries and periodontal inflammation. ${ }^{27}$ In another study that compared the methods for polishing of a provisional prosthetic material, surface-roughness values above this limit were found to range from 0.22 to 1.44 for the bysacrylic resin. ${ }^{28}$ However, the incorporation of chitosan and/or nanodiamond in a bisacrylic resin exhibited alteration in the color-stability values after storage in different solutions, which rejected the first null hypothesis in this study. The best color-stability was found after storage in distilled water (5.24 \pm 2.13$)$; however, this color-stability value was clinically perceptible because $\Delta E>3.3$ is considered to be the upper limit of acceptability in subjective visual evaluations. ${ }^{29}$

Nanodiamonds have become one of the most studied nanomaterials for incorporation in polymeric matrix because they can improve its mechanical strength. ${ }^{13}$ Furthermore, nanodiamond fillers are being employed in biological application owing to their biocompatibility, ${ }^{15}$ and the potential application of these materials as antimicrobial agent can be explored. Nanodiamonds are carbon nanoparticles with a diamond-like octahedral structure with a diameter of approximately 2 to $8 \mathrm{~nm}$. These fillers also have a strong tendency to aggregate in order to reduce the surface energy..$^{14}$ In this condition, studying whether these nanofillers can increase the surface roughness of a material would be important. In the present research, no statistical differences were found in both $R a$ and $R z$ values (Tables 2 and 3) in comparison with the control group, probably because of the small size of the incorporated fillers. Although a slightly rougher surface was found, especially after the red-wine storage, which could result in the increase in the biofilm accumulation, the antibacterial effect of the nanodiamonds can compensate for the higher surface roughness found in this group. Furthermore, a deleterious effect of a rougher surface on the color stability was not found in this research because the nanodiamond-modified material did not show any statistical difference from the control group in terms of the $\Delta E$ values.

The addition of chitosan to the bisacrylic resin did not change the surface-roughness values as well as the color stability compared with those in the control group. Chitosan is a highly charged molecule formed by the presence of bridges of hydrogen and hydroxyl groups in its polymer chain. ${ }^{30}$ The beneficial 

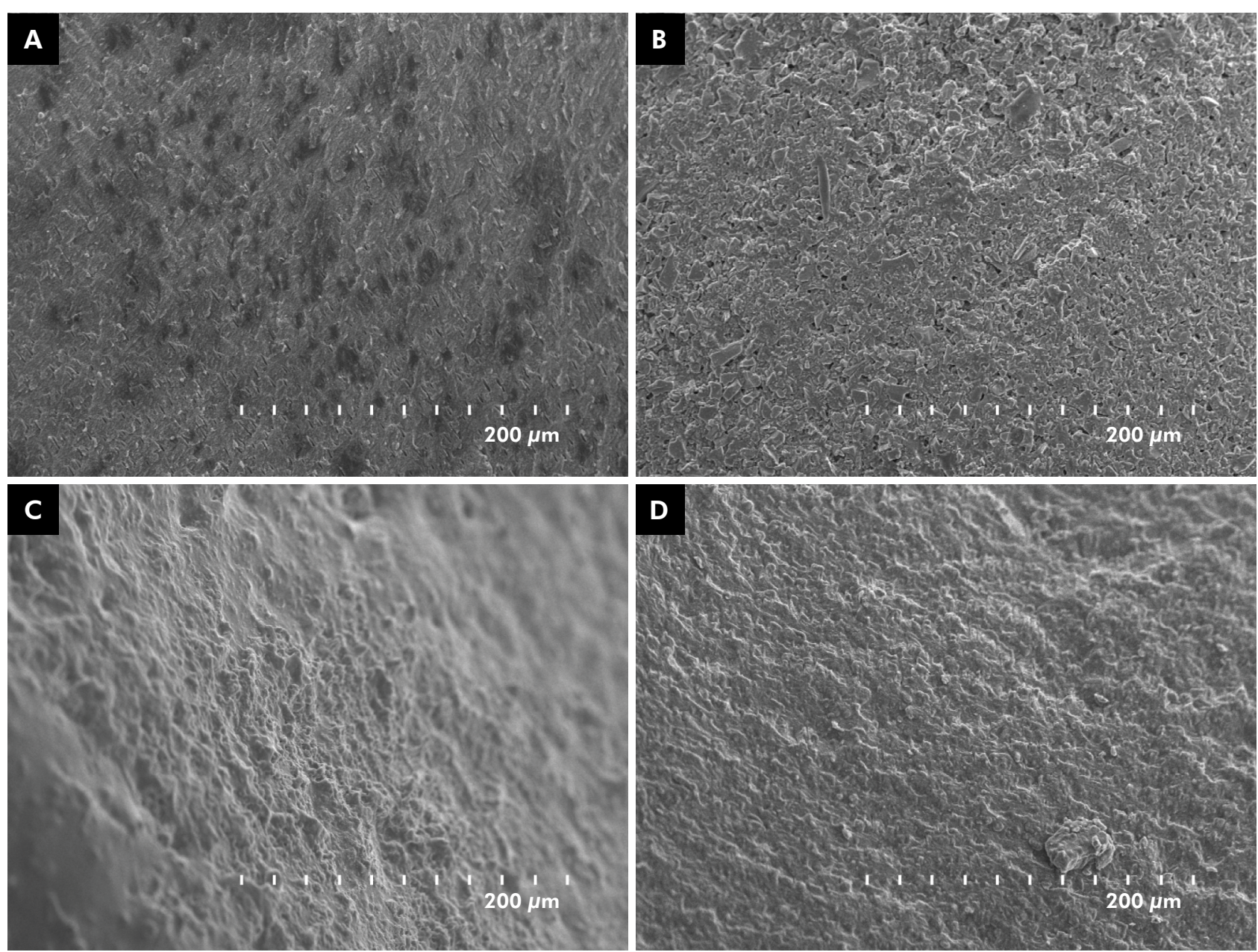

Figure. (a) SEM image of the surface of control specimen; (b) SEM image of the surface of chitosan-modified material specimen; (c) SEM image of the surface of nanodiamond-modified material specimen; (d) SEM image of the surface of chitosan-nanodiamondmodified material specimen.

effect of the incorporation of this polysaccharide as a recognized antibacterial effect ${ }^{23}$ can provide a clinical advantage to provisional materials. The antimicrobial activity of chitosan and its derivatives against bacteria, yeast, and fungi has received special attention. This antimicrobial activity depends on several factors such as the type of chitosan, $\mathrm{pH}$ of the medium, temperature, and other factors. ${ }^{31}$ The occurrence of a change in the cell permeability due to the interactions between the positive charges of chitosan and the negative charges of the cell surface was believed to result in the leakage of intracellular constituents. In the present study, although no statistical difference was found in the color stability in the chitosan-modified material compared with that in the control group, a higher color stability was found in the modified material, especially after the storage in distilled water and red-wine solutions. The methacrylation of low-molecular-weight chitosan and its incorporation into the polymer network of composites and adhesives have produced stable materials after storage in water, ${ }^{32}$ which could explain the results of the present research.

The interaction of chitosan with other biomaterials such as nanodiamond is important to improve its biological and mechanical properties for clinical applications. ${ }^{31}$ The chitosan-nanodiamond-modified material showed higher color stability compared with other materials, which can be a viable clinical alternative by combining the mechanical benefits 
Table 5. Mean and standard deviation of the three color parameters $\left(\Delta \mathrm{L}^{*}, \Delta \mathrm{a}^{*}\right.$ and $\left.\Delta \mathrm{b}^{*}\right)$ of the materials after aging in different solutions.

\begin{tabular}{lcccccccccc}
\hline \multirow{3}{*}{ Variable } & \multicolumn{3}{c}{ Distilled water } & \multicolumn{3}{c}{ Cola } & \multicolumn{3}{c}{ Red wine } \\
\cline { 2 - 9 } & $\Delta \mathrm{L}^{*}$ & $\Delta \mathrm{a}^{*}$ & $\Delta \mathrm{b}^{*}$ & $\Delta \mathrm{L}^{*}$ & $\Delta \mathrm{a}^{*}$ & $\Delta \mathrm{b}^{*}$ & $\Delta \mathrm{L}^{*}$ & $\Delta \mathrm{a}^{*}$ & $\Delta \mathrm{b}^{*}$ \\
\hline \multirow{2}{*}{ Control } & $-1.53 \pm$ & $0.26 \pm$ & $-0.48 \pm$ & $-1.54 \pm$ & $-0.23 \pm$ & $0.07 \pm$ & $-10.49 \pm$ & $0.96 \pm$ & $0.66 \pm$ \\
& 15.07 & 1.83 & 3.36 & 13.42 & 1.17 & 3.36 & 7.67 & 0.58 & 1.48 & -17.48 \\
Chitosan-modified material & $-8.51 \pm$ & $0.73 \pm$ & $-1.66 \pm$ & $-13.85 \pm$ & $1.37 \pm$ & $-1.84 \pm$ & $-6.79 \pm$ & $1.49 \pm$ & $1.33 \pm$ \\
& 4.07 & 0.44 & 1.11 & 8.86 & 0.82 & 2.38 & 4.37 & 0.37 & 1.59 \\
Nanodiamond-modified material & $-2.95 \pm$ & $0.07 \pm$ & $0.25 \pm$ & $-6.72 \pm$ & $0.19 \pm$ & $-0.63 \pm$ & $-5.96 \pm$ & $0.47 \pm$ & $1.78 \pm$ \\
Chitosan- nanodiamond-modified & 10.38 & 0.35 & 2.40 & 6.34 & 0.27 & 2.42 & 13.30 & 1.43 & 3.16 \\
material & $-1.71 \pm$ & $0.36 \pm$ & $0.06 \pm$ & $-1.78 \pm$ & $0.03 \pm$ & $0.49 \pm$ & $-4.65 \pm$ & $1.09 \pm$ & $1.52 \pm$ \\
\hline
\end{tabular}

of the nanodiamond and the biological properties of chitosan because no relevant modification in the surface roughness was also found. Another benefit of the incorporation of both materials is that the chitosan-nanodiamond composites have a relatively low agglomeration and good dispersion of the fillers, which provide a larger surface area of nanocomposites to form a stronger composite material. ${ }^{14}$

The storage of the samples in the red-wine solution resulted in an increase in the surface-roughness values of the nanodiamond-modified material compared with the other aging solutions, which rejected the second null hypothesis in this study. In the same manner, the storage in the cola soft drinks resulted in higher color alteration of the chitosan-modified material. Probably, the low $\mathrm{pH}$ of the cola soft drinks causes softening of the matrix. A loss in the structural ions occurred, and it decreased the wear resistance of the materials. ${ }^{26}$ Furthermore, the alcohol molecules could have been absorbed by the resinous matrix, which modified the material surface, and the bisacrylic resin could have become more softened, which contributed to the generally higher surface-roughness values found in the materials after storage in red wine. ${ }^{26}$ When parameters $L^{*}$, $a^{*}$ and $b^{*}$ were separately analyzed (Table 5), we observed that the values of most parameters in the cola and red-wine solution were higher than those in the distilled water independent of the material.

Under this condition, the modification of bisacrylic resin using chitosan-nanodiamonds appears to do not generally prejudice the color stability and surface roughness compared with the control group. The clinical application of these materials can be potentially viable because they can increase their mechanical and biological properties. Other studies, especially involving long-term analysis, should also be considered.

The incorporation of both chitosan and nanodiamonds can provide a better color stability to the bisacrylic resin. The incorporation of only the nanodiamond demonstrated generally higher surface-roughness values of the materials, especially after storage in the red wine. Both chitosan and nanodiamonds showed potential to provide improvement in the properties of the bisacrylic resin when simultaneously incorporated inside the product.

\section{Acknowledgments}

The authors would like to thank Dr. S. Zhang of the Department of Materials, East China University of Technology (Shanghai, China) for the SEM images.

\section{References}

1. Burke FJ, Murray MC, Shortall AC. Trends in indirect dentistry: 6. Provisional restorations, more than just a temporary. Dent Update. 2005 Oct;32(8):443-4. https://doi.org/10.12968/denu.2005.32.8.443 
2. Loshaek S, Fox T. Cross-linked polymers. I. Factors influencing the efficiency of cross-linking in copolymers of methyl methacylate and glycol dimethacrylates. J Am Chem Soc. 1953;75(14):3544-50. https://doi.org/10.1021/ja01110a068

3. Venhoven BA, de Gee AJ, Davidson CL. Polymerization contraction and conversion of light-curing BisGMA-based methacrylate resins. Biomaterials. 1993 Sep;14(11):871-5. https://doi.org/10.1016/0142-9612(93)90010-Y

4. Peutzfeldt A. Resin composites in dentistry: the monomer systems. Eur J Oral Sci. 1997 Apr;105(2):97-116. https://doi.org/10.1111/i.1600-0722.1997.tb00188.x

5. Kim SH, Watts DC. Polymerization shrinkage-strain kinetics of temporary crown and bridge materials. Dent Mater. 2004 Jan;20(1):8895. https://doi.org/10.1016/S0109-5641(03)00101-5

6. Dubois RJ, Kyriakakis P, Weiner S, Vaidyanathan TK, Dubois RJ, Kyriakakis P, et al. Effects of occlusal loading and thermocycling on the marginal gaps of light-polymerized and autopolymerized resin provisional crowns. J Prosthet Dent. 1999 Aug;82(2):161-6. https://doi.org/10.1016/S0022-3913(99)70150-2

7. Hoshiai K, Tanaka Y, Hiranuma K. Comparison of a new autocuring temporary acrylic resin with some existing products. J Prosthet Dent. 1998 Mar;79(3):273-7. https://doi.org/10.1016/S0022-3913(98)70237-9

8. Koumjian JH, Holmes JB. Marginal accuracy of provisional restorative materials. J Prosthet Dent. 1990 Jun;63(6):639-42. https://doi.org/10.1016/0022-3913(90)90320-C

9. Ehrenberg D, Weiner GI, Weiner S. Long-term effects of storage and thermal cycling on the marginal adaptation of provisional resin crowns: a pilot study. J Prosthet Dent. 2006 Mar;95(3):230-6. https://doi.org/10.1016/i.prosdent.2005.12.012

10. Almeida CS, Amaral M, de Cássia Papaiz Gonçalves F, de Arruda Paes-Junior TJ. Effect of an experimental silica-nylon reinforcement on the fracture load and flexural strength of bisacrylic interim partial fixed dental prostheses. J Prosthet Dent. 2016 Mar;115(3):301-5. https://doi.org/10.1016/i.prosdent.2015.08.009

11. Protopapa P, Kontonasaki E, Bikiaris D, Paraskevopoulos KM, Koidis P. Reinforcement of a PMMA resin for fixed interim prostheses with nanodiamonds. Dent Mater J. 2011;30(2):222-31. https://doi.org/10.4012/dmi.2010-135

12. Härtl A, Schmich E, Garrido JA, Hernando J, Catharino SC, Walter S, et al. Protein-modified nanocrystalline diamond thin films for biosensor applications. Nat Mater. 2004 Oct;3(10):736-42. https://doi.org/10.1038/nmat1204

13. Perchyonok V, Souza T, Felliti R, Zhang S, Grobler S. Bio-functional nanodiamond restorative materials containing bio-additives: in vitro approach. Open J Stomatol. 2015;5(5):117-26. https://doi.org/10.4236/ojst.2015.55017

14. Sun $Y$, Yang Q, Wang $H$. Synthesis and characterization of nanodiamond reinforced chitosan for bone tissue engineering. J Funct Biomater. 2016 Sep;7(3):E27. https://doi.org/10.3390/jfb7030027

15. Krueger A. New carbon materials: biological applications of functionalized nanodiamond materials. Chemistry. 2008;14(5):1382-90. https://doi.org/10.1002/chem.200700987

16. Al-Harbi FA, Abdel-Halim MS, Gad MM, Fouda SM, Baba NZ, AlRumaih HS, et al. Effect of nanodiamond addition on flexural strength, impact strength, and surface roughness of PMMA denture base. J Prosthodont. 2019 Jan;28(1):e417-25. https://doi.org/10.1111/jopr.12969

17. Gillissen A, Nowak D. Characterization of N-acetylcysteine and ambroxol in anti-oxidant therapy. Respir Med. 1998 Apr;92(4):609-23. https://doi.org/10.1016/S0954-6111(98)90506-6

18. Goodman SB, Schatzker J, Sumner-Smith G, Fornasier VL, Goften N, Hunt C. The effect of polymethylmethacrylate on bone: an experimental study. Arch Orthop Trauma Surg. 1985;104(3):150-4. https://doi.org/10.1007/BF00454691

19. Amir LR, Suniarti DF, Utami S, Abbas B. Chitosan as a potential osteogenic factor compared with dexamethasone in cultured macaque dental pulp stromal cells. Cell Tissue Res. 2014 Nov;358(2):407-15. https://doi.org/10.1007/s00441-014-1938-1

20. Arancibia R, Maturana C, Silva D, Tobar N, Tapia C, Salazar JC, et al. Effects of chitosan particles in periodontal pathogens and gingival fibroblasts. J Dent Res. 2013 Aug;92(8):740-5. https://doi.org/10.1177/0022034513494816

21. Diolosà M, Donati I, Turco G, Cadenaro M, Di Lenarda R, Breschi L, et al. Use of methacrylate-modified chitosan to increase the durability of dentine bonding systems. Biomacromolecules. 2014 Dec;15(12):4606-13. https://doi.org/10.1021/bm5014124

22. Senel S, Ikinci G, KaşS, Yousefi-Rad A, Sargon MF, Hincal AA. Chitosan films and hydrogels of chlorhexidine gluconate for oral mucosal delivery. Int J Pharm. 2000 Jan;193(2):197-203. https://doi.org/10.1016/S0378-5173(99)00334-8

23. Yadav AV. Bhise. B. Chitosan: a potencial biomaterial effective against typhoid. Curr Sci. 2004;87(9):1176-8.

24. Husain S, Al-Samadani KH, Najeeb S, Zafar MS, Khurshid Z, Zohaib S, et al. Chitosan biomaterials for current and potencial dental applications. Materials (Basel). 2017 May;10(6):E602. https://doi.org/10.3390/ma10060602

25. Catelan A, Suzuki TY, Becker F Jr, Briso AL, Dos Santos PH. Influence of surface sealing on color stability and roughness of composite submitted to ultraviolet-accelerated aging. J Investig Clin Dent. 2017 May;8(2):e12203. https://doi.org/10.1111/jicd.12203

26. Catelan A, Briso AL, Sundfeld RH, Goiato MC, Santos PH. Color stability of sealed composite resin restorative materials after ultraviolet artificial aging and immersion in staining solutions. J Prosthet Dent. 2011 Apr;105(4):236-41. https://doi.org/10.1016/S0022-3913(11)60038-3 
27. Bollen CM, Lambrechts P, Quirynen M. Comparison of surface roughness of oral hard materials to the threshold surface roughness for bacterial plaque retention: a review of the literature. Dent Mater. 1997 Jul;13(4):258-69. https://doi.org/10.1016/S0109-5641(97)80038-3

28. Tupinambá ÍV, Giampá PC, Rocha IA, Lima EM. Effect of different polishing methods on surface roughness of provisional prosthetic materials. J Indian Prosthodont Soc. 2018 Apr-Jun;18(2):96-101. https://doi.org/10.4103/iips.jips_258_17

29. Um CM, Ruyter IE. Staining of resin-based veneering materials with coffee and tea. Quintessence Int. 1991 May;22(5):377-86.

30. Ururahy MS, Curylofo-Zotti FA, Galo R, Nogueira LF, Ramos AP, Corona SA. Wettability and surface morphology of eroded dentin treated with chitosan. Arch Oral Biol. 2017 Mar;75:68-73. https://doi.org/10.1016/i.archoralbio.2016.11.017

31. Qin C, Xiao Q, Li H, Fang M, Liu Y, Chen X, et al. Calorimetric studies of the action of chitosan-N-2-hydroxypropyl trimethyl ammonium chloride on the growth of microorganisms. Int J Biol Macromol. 2004 Apr;34(1-2):121-6. https://doi.org/10.1016/i.ijbiomac.2004.03.009

32. Stenhagen IS, Rukke HV, Dragland IS, Kopperud HM. Effect of methacrylated chitosan incorporated in experimental composite and adhesive on mechanical properties and biofilm formation. Eur J Oral Sci. 2019 Feb;127(1):81-8. https://doi.org/10.1111/eos.12584 